\title{
Incorporating Social Factors in Accessible Design
}

\author{
Kristen Shinohara ${ }^{1}$, Jacob O. Wobbrock ${ }^{2}$, Wanda Pratt ${ }^{2}$ \\ ${ }^{1}$ B. Thomas Golisano College of \\ Computing \& Information Sciences \\ Rochester Institute of Technology \\ Rochester, NY, USA 14623 \\ kristen.shinohara@rit.edu \\ ${ }^{2}$ The Information School \\ DUB Group \\ University of Washington \\ Seattle, WA, USA 98195-2840 \\ \{wobbrock,wpratt\}@uw.edu
}

\begin{abstract}
Personal technologies are rarely designed to be accessible to disabled people, partly due to the perceived challenge of including disability in design. Through design workshops, we addressed this challenge by infusing user-centered design activities with Design for Social Accessibility-a perspective emphasizing social aspects of accessibility - to investigate how professional designers can leverage social factors to include accessibility in design. We focused on how professional designers incorporated Design for Social Accessibility's three tenets: (1) to work with users with and without visual impairments; (2) to consider social and functional factors; (3) to employ tools-a framework and method cards - to raise awareness and prompt reflection on social aspects toward accessible design. We then interviewed designers about their workshop experiences. We found DSA to be an effective set of tools and strategies incorporating social/functional and non/disabled perspectives that helped designers create accessible design.
\end{abstract}

\section{CCS Concepts}

- Human-centered computing Accessibility design and evaluation methods $•$ Human-centered computing $\sim$ User centered design

\section{Author Keywords}

Design workshops, accessibility, user-centered design.

\section{INTRODUCTION}

People with disabilities rely on the accessibility of a technology to be able to use it. Yet, many mainstream personal technologies are not readily accessible to people with disabilities without additional accommodation. Accessibility research offers several approaches to promote inclusive design $[19,23,28,35,36]$, and popular user interface and user experience (UI/UX) design approaches rely on "user-centered" strategies to include disabled users to achieve accessible design [27]. Although research

Permission to make digital or hard copies of all or part of this work for personal or classroom use is granted without fee provided that copies are not made or distributed for profit or commercial advantage and that copies bear this notice and the full citation on the first page. Copyrights for components of this work owned by others than ACM must be honored. Abstracting with credit is permitted. To copy otherwise, or republish, to post on servers or to redistribute to lists, requires prior specific permission and/or a fee. Request permissions from Permissions@acm.org.

ASSETS '18, October 22-24, 2018, Galway, Ireland

(C) 2018 Association for Computing Machinery.

ACM ISBN 978-1-4503-5650-3/18/10 ..\$15.00

https://doi.org/10.1145/3234695.3236346 demonstrates the value of designing accessible technologies for people with disabilities [23], the lack of accessible personal technologies on the market indicates that few working designers include disabled users in everyday practice. Despite efforts in the research domain to improve accessible design $[24,35,36]$, influencing designers' actual practice remains challenging $[13,32]$.

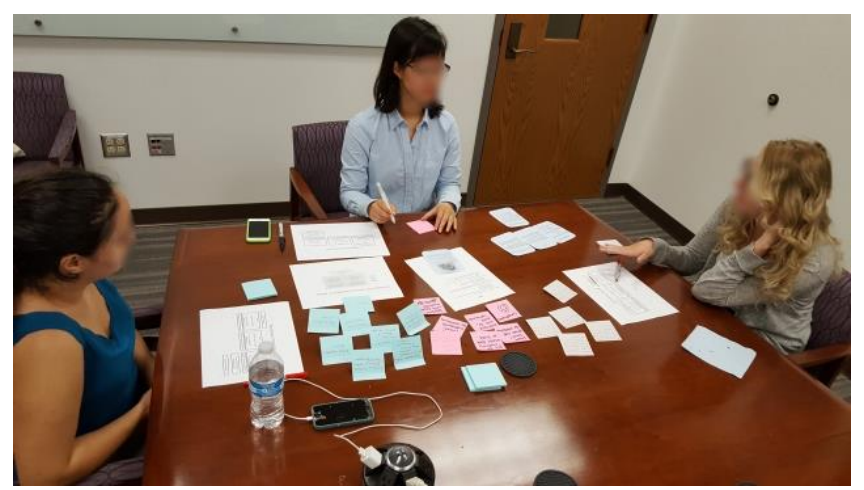

Figure 1. A professional designer (center) brainstorms with two users, one with a visual impairment (left) and one without (right).

Design for Social Accessibility (DSA) is one approach that targets how designers address accessible design by focusing on social and functional factors [28,31]. Prior research developing DSA found that engaging multiple disabled and nondisabled users and emphasizing social aspects of design helped student designers align with diverse needs $[28,29,30,31]$. In this study, we extended prior work and developed a framework and set of method cards to investigate how professional designers, rather than students, incorporate DSA to create accessible design. We asked: How effective is DSA in helping professional designers (1) include social factors to create accessible designs, and (2) work with multiple non/disabled users? We also sought to learn from professional designers' experiences, as opposed to students, and asked: what key considerations do designers make when tackling social factors in accessible design?

We conducted workshops infusing user-centered design (UCD) with DSA [28,29] to examine if incorporating social factors and multiple perspectives helped professional designers include accessibility in their design work (Figure 1). We scaffolded workshop activities with DSA's three tenets: (1) design for disability should include disabled and nondisabled users [29]; (2) design should address social and 
functional factors simultaneously [31]; and (3) design should include tools to prompt consideration of social factors in accessible design [28]. We analyzed the workshops along these tenets, examining: (1) interactions between designers and users; (2) social considerations and design decisions; and (3) ways that designers used tools to facilitate social factors in accessible design. We found that colocated users, and the DSA framework and method cards, enabled designers to elicit considerations for social aspects of accessibility that were more than the sum of users' perspectives and that helped create accessible design.

\section{RELATED WORK}

We draw on certain assertions about accessible design: first, social consideration benefits accessible design because it takes into account shared and unique social values of diverse users [31]; broadening perspectives - to include social and functional factors and disabled and nondisabled usersencourages inclusive design [29]. Second, that professional designers have skill to tackle social and functional factors $[6,22]$. We refer to "accessible design" as technologies designed to be usable by disabled people, to disambiguate from mainstream designs that tend not to be inclusive.

\section{Technology Design and Disability}

Design thinking is a popular approach to create new ideas and artifacts [3,7]. User-centered design (UCD) facilitates design thinking by placing human needs, goals, and desires at the core of iterative processes [3,14,27]. A key tenet of $\mathrm{UCD}$ is that, by virtue of placing the user at the center of the design process, specific and diverse user characteristics can be addressed [14]. For example, interviewing and user testing with people with disabilities is likely to result in more accessible designs [27]. However, a user-centered approach only centers disabled people in the process if designers desire accessible outcomes. Indeed, unless prompted, student designers tend to assume that nondisabled users are the de facto target audience [29], and the dearth of accessible technologies indicates that few designers center disabled and nondisabled perspectives.

To combat approaches that omit disabled users, researchers developed strategies to include disability in design. UserSensitive Inclusive Design advocates social engagement to help designers become familiar with disabled users, their needs and desires [23]. Design for User Empowerment recognizes that increasing the number of disabled designers and engineers will improve the number and quality of accessible technologies [19]. Ability-Based Design centers on what users can do rather than on specific impairments or limitations, advocating for systems that can sense, understand, and possibly adapt to users' abilities [35,36]. Universal Design emphasizes design for as many users as possible, through removing barriers to access [4,5]. In practice, designers employing Universal Design may face difficulty finding solutions that address a wide range of diverse abilities [28]. These approaches are meant to ameliorate the lack of accessibility in mainstream UCD, though there is some concern that emphasizing disability may lead to designs only for disabled users, not necessarily increasing mainstream accessibility $[1,10]$.

Diverse design approaches herald that accessibility can be combined with innovative intelligent and autonomous computing to increase accessibility in all technologies. Recent advances in intelligent and autonomous computing, (e.g., Siri, Cortana, Alexa, HoloLens, Oculus Rift, selfdriving cars) have potential to facilitate alternative access to information (e.g., voice commands [17]) and to the user's environment (virtual/augmented reality [16]). For example, the Apple iPhone has built-in accessibility features, such as the VoiceOver screen-reading system. New opportunities arise as technologies evolve, e.g., autonomous vehicles may increase transportation options for those unable to drive $[2,9,26,34]$, or telepresence robots could reduce the need to travel $[18,33]$. New technologies are opportunities to include accessibility in mainstream design, yet few professional designers avail themselves of these advances to produce designs accessible to disabled users $[9,20]$.

We regard professional designers' expertise as built on skill and knowledge that prepares them "for action," and seek not to impose an approach that oversteps their judgment $[13,32]$. By investigating how professional designers, rather than students, infuse UCD with DSA, we seek to understand how experienced designers - established in their design practice $[7,22,32]$ — include multiple diverse views and social factors, and use new tools to aid these endeavors [32].

\section{Social Aspects of Accessibility}

Prior work found that social factors influence how disabled people choose to use their technologies, often affecting access [30]. Technology presentation, use, and perception by others plays a role in access, i.e., when users feel selfconfident or self-conscious about using their devices [31]. In one study, considering social perspectives from both disabled and nondisabled users allowed student designers to better address requirements for accessible design [28,29]. The shared understanding of social expectations (i.e., decorum) between non/disabled users could be leveraged to address social factors in accessible design [28], what we call Social Accessibility. What has not been examined is how professional designers include social aspects in accessible design, and if tools could be developed that promote a "prepared-for-action" approach.

In this paper, "socially usable" refers to how usable something is within a social context as a social object, not a functional one, e.g., when fashionable heels that are painful are preferred for "the look" one is trying to achieve. The shoes' social value outshines their functionality. "Socially accessible" designs are those that are socially usable and also fulfill a functional objective. In the heels example, insoles might provide support, adding functional comfort to the fashionable shoe. We define "socially" acceptable as when an object, person, or circumstance is considered to be within the social norms of a given community. Norms are 
"accepted" ideals implicitly established by community consensus [25], that, by definition, create the possibility of deviance [8]. Technology perception and preference emerge from our understanding of socially defined norms [12].

\section{DESIGN WORKSHOPS}

We conducted five, three-hour design workshops, infused with Design for Social Accessibility (DSA), to observe how including social factors and multiple perspectives help designers create accessible designs. Designers worked with users with and without visual impairments in a user-centered design (UCD) process infused with the DSA tenets described above. DSA incorporates social factors with tools and strategies to engage designers and users around social expectations of technology use, first by co-locating designers and users, then by giving designers a framework-to visualize a design space of functional and social factorsand method cards - to ask about social scenarios, e.g., a professional environment. After each workshop, we interviewed designers about their experience to understand how they approached accessibility, and to learn their views on working with visually impaired users and with disabled users overall. We asked designers, "What was it like to work with both users?" and "How did the workshop compare to your typical design work?"

We provided materials for the workshops, although a few designers brought their own pencils and sketch pads. We supplied a variety of basic office supplies to work with, including index cards, Post-It notes, Scotch tape, glue sticks, markers, highlighters, pens, and paper clips. Designers also had access to a white board and large conference table. The first author set up the workshop, gave the prompt, answered clarifying questions, and timed each session. The first author observed, and did not intervene, while tasks were completed.

\section{Participants}

One designer led the tasks in each workshop, working with two users simultaneously: a visually impaired and a sighted user, for a total of 15 study participants (Table 1). Designers had at least three years of professional UI/UX or industrial design experience, and visually impaired users ranged from low-vision to blind. We recruited designers who were not accessibility experts to explore how general designers approach accessibility. Users did not have design experience and were introduced as having the "user expertise" to contribute. We restricted our study to two users per workshop because designers might not typically have access to many people with visual impairments.

\section{The Workshops}

We structured workshops around common UCD activities: brainstorming, synthesis, prototyping, evaluation. We encouraged designers to use techniques they typically use and to engage users as needed, in service of creating a paper prototype representing the final design. Designers engaged users and elicited feedback as befit their own style, rather than systematically involving users, as is typical in participatory design [15]. Workshops were three hours long; each phase approximately 20 to 30 minutes of design time. Time limits were imposed because the main goal was to determine if designers could progress toward accessible design, not necessarily to have a refined solution.

\begin{tabular}{|c|l|l|c|}
\hline $\begin{array}{c}\text { Work- } \\
\text { shop }\end{array}$ & $\begin{array}{c}\text { Designer (D) } \\
\text { Title-Yrs. Experience }\end{array}$ & $\begin{array}{c}\text { Visually Impaired } \\
\text { User (V) }\end{array}$ & $\begin{array}{c}\text { Sighted } \\
\text { User (S) }\end{array}$ \\
\hline 1 & $\begin{array}{l}\text { D1 (F, 25 yrs) } \\
\text { Product Designer-6 yrs }\end{array}$ & $\begin{array}{l}\text { V1 (F, 20 yrs) } \\
\text { low vision }\end{array}$ & S1 (F, 24 yrs) \\
\hline 2 & $\begin{array}{l}\text { D2 (M, 31 yrs) } \\
\text { Senior Designer-5 yrs }\end{array}$ & $\begin{array}{l}\text { V2 (F, 54 yrs) } \\
\text { low vision }\end{array}$ & S2 (F, 29 yrs) \\
\hline 3 & $\begin{array}{l}\text { D3 (F, 54 yrs) } \\
\text { Designer-5 yrs }\end{array}$ & $\begin{array}{l}\text { V3 (F, 34 yrs) } \\
\text { light/dark vision }\end{array}$ & S3 (F, 37 yrs) \\
\hline 4 & $\begin{array}{l}\text { D4 (M, 44 yrs) } \\
\text { IT Consultant-5 yrs }\end{array}$ & V4 (F, 63 yrs), blind & S4 (F, 34 yrs) \\
\hline 5 & $\begin{array}{l}\text { D5 (F, 25 yrs) } \\
\text { Technical Designer-3 yrs }\end{array}$ & $\begin{array}{l}\text { V5 (M, 32 yrs), } \\
\text { Stargardt's, no central } \\
\text { vision }\end{array}$ & S5 (F, 18 yrs) \\
\hline
\end{tabular}

Table 1. Workshop participants.

In the brainstorming phase, we instructed designers to ideate to the given prompt, described below. In the synthesis phase, we asked designers to narrow ideas into a final idea to be prototyped. In the prototyping phase, designers prototyped a crude paper manifestation of their idea (Figure 2). In the evaluation phase, designers and users tested the prototypes via a brief evaluation task (Figure 3 ). Testing was not formal, but was an opportunity for participants to reflect and assess how the design met user needs. After each phase, designers and users were led to separate locations to briefly respond to reflection prompts about their experiences during that phase. Participants were separated because reflection prompts asked feedback on working with the others and on how they thought the design was progressing. After completing reflections and before each new session, participants gathered again in the conference room. After the workshops, users evaluated how well the solution addressed their needs, and reflected on their experience working with the designers.

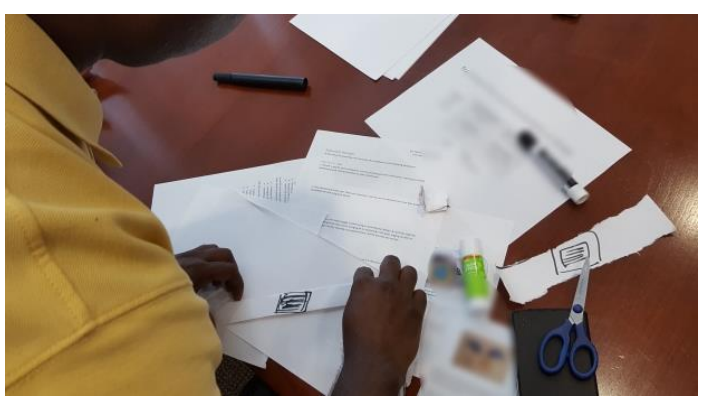

Figure 2. D2 puts together a paper prototype.

We prompted designers to create an on-body device for cruise ship passengers to track information, such as money spent, or location and times of on-board activities. The solution had to also be usable by sighted and visually impaired users. In formulating the design prompt for this study, we solicited ideas from blind and visually impaired listservs and contacts. Broadly, we asked, "What kinds of problems do you think technology designers should be addressing?" specifically asking about technology use in social spaces. We received a "brain-dump" of issues which 
we then categorized by technologies. We defined a domain comprising issues uncovered in related work, i.e., users, technologies, places, and situations of use [30,31], and designed and piloted the prompt based on these constructs with graduate design and HCI students. We focused on an atypically inclusive environment where non-phone device or application would constitute a plausible solution.

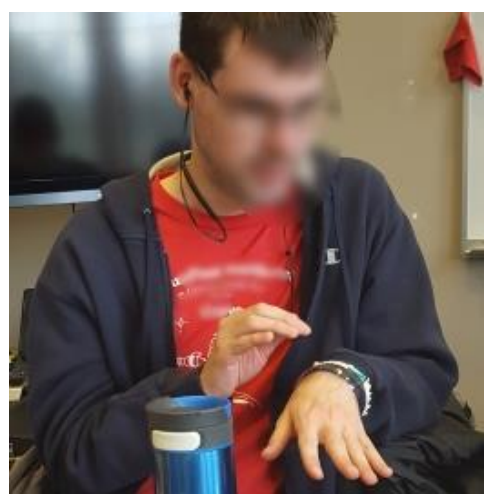

Figure 3. V5 tests a prototype (on his wrist).

\section{Tools}

We gave designers the DSA framework (Figure 4) and method cards (Figure 5) to scaffold social factors and prompt awareness of technology use in different contexts, respectively. The framework outlines a conceptual domain for socially accessible design by emphasizing that social and functional factors together contribute to how accessible a design may be. The method cards incorporate themes and findings from prior work to prompt designers to consider complex social situations of technology use. Designers were instructed to use the tools as they saw fit to help social consideration, so that we might learn how the tools fit within designers' own practice. Details on the conceptual origins of these tools can be found in related work [28,29].

\section{Data and Analysis}

Data consisted of designer interview transcripts, workshop video and transcripts, and design artifacts. We open coded interview and workshop data [11,21], and observation notes and memos were analyzed and compared with emergent themes [21]. Qualitative analysis then focused on the DSA tenets examining: (1) how designers engaged both users, (2) how social considerations were included, and (3) how designers used the framework and method cards. Specifically, did DSA align with designers' expertise? Key themes that emerged include how tools enabled exploration of intersectional ideas (e.g., "duality," coined by S5 to describe how they identified features for sighted and visually impaired users), how the framework guided social consideration, and how cards provided concrete prompts for social contexts. A second, deductive analytic pass was made - transcripts were re-coded and compared with themes from prior work-focused on social factors in the design process. Themes confirmed prior work that users were sensitive to how designs operated in social contexts. Users did not always agree on what was useful for them, but they came to consensus to create useful and appealing designs for visually impaired and sighted users; participant ideas built on prior themes that disabled users should have designs with socio-technical appeal "just like everyone else."

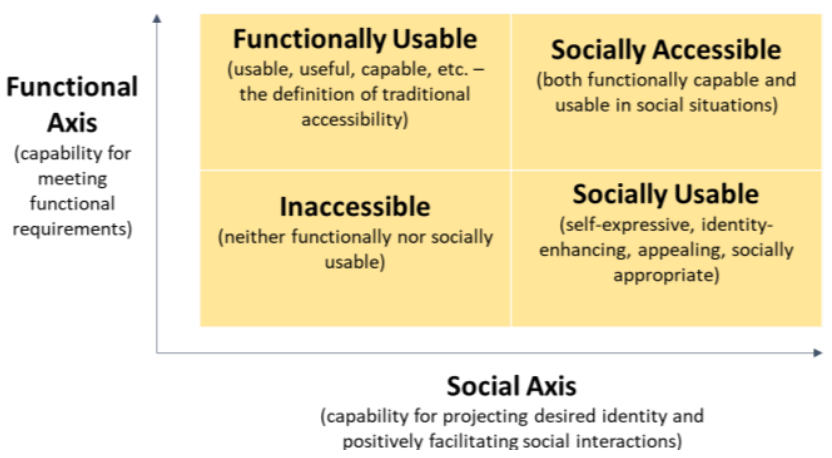

Figure 4. The Design for Social Accessibility framework [28] given to designers outlines a spatial guide to optimize and isolate design decisions along social and functional dimensions.
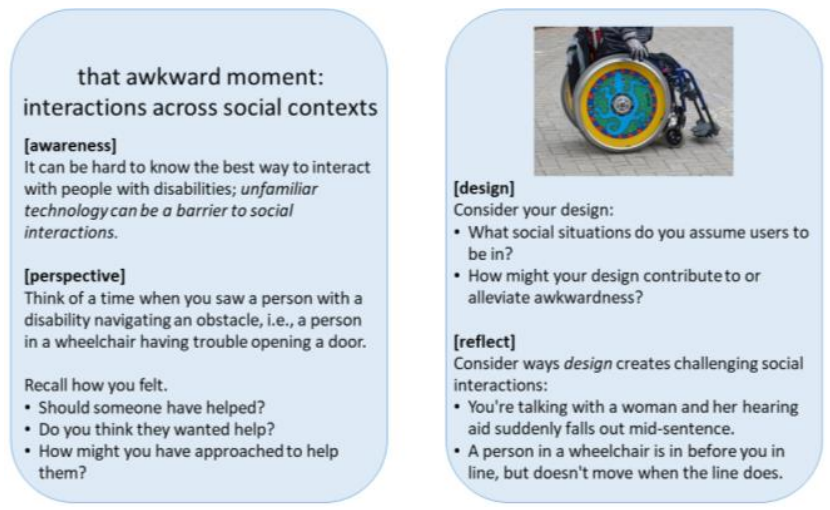

Figure 5. The Design for Social Accessibility method card titled, "that awkward moment." Due to space limitations, we show here one of the set of five method cards used by designers to prompt reflection on social and accessible challenges.

\section{FINDINGS}

We investigated how effective Design for Social Accessibility (DSA) was in helping designers (1) include social factors and (2) work with visually impaired and sighted users. We found that the framework and method cards, social consideration, and colocation helped designers manage intersecting perspectives toward accessible design.

\section{Reflection with Framework and Method Cards}

The framework and method cards helped designers leverage discussions about socially accessible design, which elicited user preferences based on personal social experiences.

\section{Framework as Domain Space}

Designers used the framework to communicate how the social and functional dimensions comprise a domain space of social accessibility. D1 drew the framework on the whiteboard, and placed Post-It notes with ideas on it, arranging them along the social and functional axes according to the group's discussions (Figure 6). She then referred to the framework after brainstorming and during 
synthesis to assess their ideas against what might be considered socially accessible:
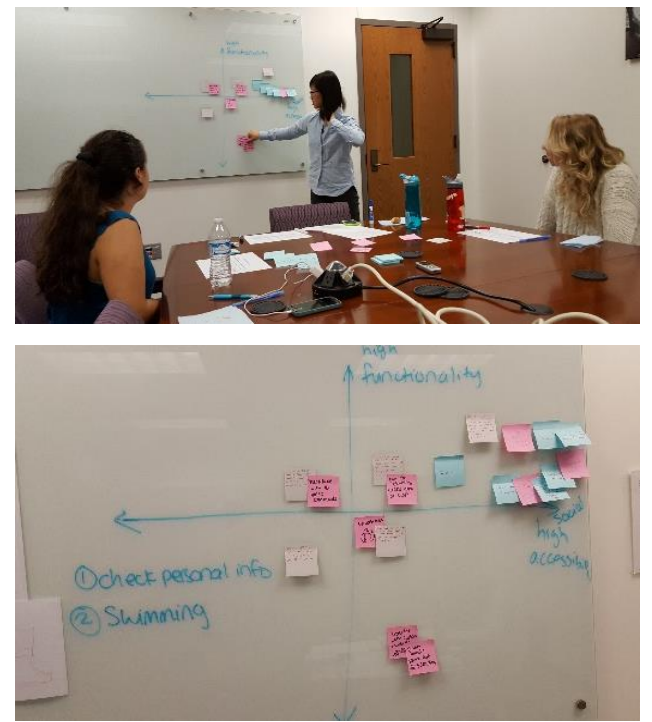

Figure 6. D1 uses the whiteboard to categorize ideas according to the Design for Social Accessibility framework.

D1: What I've done in previous places, too, like how we narrowed down the brainstorm is we plot all the ideas on a chart like this, and tech companies usually do like high to low cost and low to high user impact, but in this case, we're gonna be doing low to high functionality and then low to high social accessibility. So I'm gonna plot this on the wall and then we'll go and pick ideas and see like where they fit on that chart. [starts to place ideas on whiteboard]... Okay, so, smart watch, is it a high functionality, low functionality, like socially accessible or not? And we can be not sure about this-if we're not sure, we'll put a little-

V1: I think its moderate accessibility, with some pretty high social-

D1: So, very social and moderate functionality?

V1: yeah.

D1: Okay, so I'll put it like-I'll put it here. Something that is durable-

\section{V1: That seems-both of those can be met.}

D1: Um hm. High function and high social-okay, so it also seems to be like a quality of something that we want to have... ID card-sized tablet, but really thin that you can wear on a lanyard around your neck. So, how do you feel in terms of like functionality and social accessibility?

V1: That could be very functional, but not entirely 100\% accessible.

D1: Um hm. Okay. And let me know if you guys ever feel like something's contradicting or if you don't agree, we can always move it around. -Workshop 1, Task 2
D1 relates the task of using the framework to her prior experience charting ideas ("high to low cost and low to high user impact"), and adapts that strategy with the framework. She fits ideas in the framework, questioning out loud if ideas are high functionality or social accessibility, tempering that, "we can be not sure about this," to smooth over their decisions - they could always return to ideas after initial placement. In response, V1 assesses, "that could be very functional, but not entirely $100 \%$ accessible." It is unclear how V1 interprets access with social factors, but, for the purposes of the exercise, D1 reminded them, "we can always move it around." Whereas D1 drew on prior experiences, other designers focused on each axis, then reflected on if ideas were "socially acceptable." For example, we highlight that D4's interpretation of social accessibility, and his way of conveying how they should use these concepts.

...how functionally usable is this and the social axis, capability for projecting desired identity and positively facilitating social interactions. So... have we hit upon this up and to the right dimension. So, of a device that's socially acceptable? -D4, Workshop 5, Task 2

In his interview, D4 later explained his strategy of using the framework to define social accessibility so his team could quickly apply it.

D4: You're trying to ramp up understanding of it quickly, so trying to figure out: how can I get someone to understand these 2 dimensions so that when they see the 2 dimensions in combination in these 4 sectors, then it clicks a little quicker. And, again, this is pretty clear, I'm not-I don't want to be like, I'm not like lost here in any means. -D4, Interview.

As these examples show, we observed that the framework allowed designers to focus on social aspects, functional aspects, or both, giving flexibility while not overwhelming users and the ideation process.

\section{Method Cards as Reflection Tools}

While the framework helped designers focus on social and functional considerations, the cards illustrated how social situations influence - or are influenced by-design. All designers used the cards during brainstorming to generate ideas; some iterated on existing ideas (D3, D4). D2 read the cards to himself before asking questions. All the designers derived questions based on prompts and scenarios in the cards, although D3 attempted to derive questions only from images, which was less effective. D3 and D4 also drew on cards in iteration, asking how previously brainstormed ideas were impacted by cards' social scenarios. D1 read the description of the "Awkward Moment" card out loud (Figure 3 ), and then asked users to consider how their ideas might be affected by similar scenarios:

V1: Well, for me, if I'm going to wear the watch I'm all of a sudden going to have my fist up here (lifts wrist up in front of her face) and, uh, some people are not a fan of me not looking at them straight in the eyes. So that's something. It's 
just like (mimics looking down, closely at her wrist, laughs). That could become awkward.

D1: (turning to S1) do you have any thoughts on that? It doesn't have to be the smartwatch, but, like, any of the ideas we came up with.

S1: ...if you're walking around with your arm up trying to say it (lifts arm in front of her face) you might run into something on the ship. And you're on a ship, you're on the ocean, that could be bad. (everyone laughs). So it does definitely seem like there are problems that could arise from having something that really relies on visual but I don't quite know how to move away from the visual, either.

\section{D1: Um hm.}

V1: Well, I think, um, you know how like a mouse has one of those scroll wheels?...Um, if the watch had a little scroll... and then you had a little earpiece or something to go like this to (mimics tapping wrist) swap from topic to topic or setting to setting, that might help.

D1: Okay. So, for that idea, like a concept for some kind of physical control, not just screen based. -Workshop 1, Task 1

The prompt elicited discussion about awkward moments for V1 when "people are not a fan of me not looking at them straight in the eyes" due to her visual impairment. V1's personal experience led D1 to ask S1 her thoughts in light of a potentially awkward interaction. $\mathrm{S} 1$ conceded the situation might also pose a safety hazard. The discussion nudged the group to brainstorm other solutions, such as scroll wheels.

D5 summarized the method cards with users and debated what it meant for something to be acceptable to use in social situations. V5 pointed out that design for everyone ought to make the task simpler for the designer.

D5: There's always gonna be like fallbacks in each design, but we'll always try to create one that's-um, as best as we can with whatever we're limited to. Um, ideally, you'd want to have something just like everyone else, right?

\section{S5: ...Yeah. It wouldn't marginalize you, or anything?}

V5: yeah... and if you have something like everybody else, then it makes it easier, um, it wouldn't marginalize me, but then it would also make it easier for you as a designer, too, wouldn't it? -Workshop 5, Task 1

As the group continued to discuss the "Awkward Moment" scenario prompted by method cards, they continued to debate the notion that "special" devices for people with disabilities would single out individuals unnecessarily.

S5: So if we're looking at these other concepts like perceptions of special technology, that would, you know, create like unwanted attention, if everyone has it then it's not special anymore ...so it won't draw unwanted attention because everyone has one, right? Which is a good thing.
D5: Um hm. Yeah, it could be something that's-um, provided to you, like as you're boarding the [cruise ship]-

V5: yeah, that's actually what I was just thinking-

D5: like everybody has it. Yeah. Yeah, that way like you said we can make it just like everyone else, everybody feels like they fit in, or they won't be, um-

V5: everybody can seem like they fit in and-even if you have to use it for something slightly different.

D5: yeah, you'll still feel comfortable because someone else has it, they're not going to question what you're wearing.

\section{S5: Just like everyone else. -Workshop 5, Task 1}

Thus, prompts from the method cards encouraged discussion on personal and sensitive issues, including how technology can marginalize individuals. But, discussions focused on how to make designs socially accessible (maximizing social and functional aspects), they also addressed how to combat sensitive issues, such as deciding that the design should be for everyone and positing that such a strategy could "make it easier" for the designer.

All designers but D3 read through and prompted discussion based on the scenarios in the cards. D3 quickly skimmed and relied on the imagery of the cards to prompt conversation, an approach that was less effective because the images did not convey prompts as clearly as the text.

How Designers Include Social and Functional Factors While the framework and method cards helped participants draw on social accessibility to create accessible design, designers also relied on simple questions to ask how social and functional factors influence preferences on access issues.

Functional Consideration and Disability Knowledge Sharing Discussions often began around the visually impaired user's functional needs in an attempt to define design requirements. For example, D5 began the brainstorm session by deferring to V5's visual acuity as a baseline constraint, asking, "So what is your vision capability?" to which V5 responded, "The disease is called Stargardt's, which is the juvenile form of macular degeneration. So I have scarring over the macula, which is in the center of the eyes," providing detail about his visual abilities. But, merely understanding visual limitations would not be enough to work out nuanced scenarios. D3 tried to get a sense of what kind of indoor navigation $\mathrm{V} 3$ required:

D3: So what would happen if you said, I want to go to the casino. It would get you in the casino, but it wouldn't get you to a table, correct?

V3: No, it would not, and that's okay. As long as it gets you to the door.

D3: Okay. Okay, that's what-that's what I was envisioning is that it would actually get you in the door.

V3: After that point, you can use sighted assistance, so if I'm gonna go to the buffet, I'm obviously not just going to walk 
through the buffet, um, without making sure that I have-I have navigational help to a table. Yeah, and I would not expect my watch to do that. -Workshop 3, Task 2

As shown above, visually impaired users educated sighted participants on experiences of disability. V3 also described how her technologies worked so that the sighted user and designer could understand designs she referenced:

With VoiceOver on it that doesn't matter. I can hit anything on the screen and it doesn't change anything because I'm not activating it until I tell it to. Um, so you wanna make sure that the visually impaired users are-have a separate set of interactive things. Or you could make it more based on voice activation. I think that voice activation allows for a lot of usability. -V3, Workshop 3, Task 1

Visually impaired users were disability and accessibility experts, supplying knowledge about accessible technologies. Next, we show how these contributions shaped discussions of social issues. It is unclear how scalable it is to leverage users' knowledge. It is possible to envision users eventually experiencing fatigue as the source of such information.

\section{Social Consideration Creates Space for Duality}

Centering colocated discussions on social contexts of use helped participants align social preferences and identify a "duality" (as S5 called it, below) in the design itself - aspects where a design could be usable and appealing for both users. Workshop 5 participants narrowed the design form factor, choosing between a headband and watch:

V5:...I don't know of anybody would really wanna always like have a headband on-

D5: yeah (laughs)

V5: or something like that, yeah.

D5: a watch or-what do you think?

S5: I think the watch would probably be good and then for a person who is-like has normal sight a watch would still be like, oh I can check the time, and blah blah blah blah blah, so you can still input like visual-like, uh, like for the able bodied people, right? ...Um, and so like I think that provides a little more space for duality, so that not only allows him to find value from it, but also, um, a non-sight impaired person to find value from it, right? And so like, if he, if it's a watch that has a like a Bluetooth headset connected to it, then, um, I think like there's value for him there. And then there's also value for me in the actual watch as well, I guess. Does that make sense?

D5: Um hm. So, we talked about making this just like everyone else, and so if-what else would the watch come with?

\section{S5: probably tells the time (laughs)}

D5: Well for you to be able to hear the things that you need to navigate the cruise. Like we said that has to-does that have to come with an earbud?
V5: No, because you could just connect to using Bluetooth, that's another way that you could make it more normal or whatever. -Workshop 5, Task 2

As S5 commented, discussing social aspects of use "provides a little more space for duality" so that both visually impaired and sighted users "find value from it." We interpret "duality" as broadening form factor, capability and peripherals to accommodate more than visual impairment, but also the overall cruise experience. In this case, participants zeroed in on Bluetooth as a way to "make it more normal" because the technology is commonly used for personal audio, but it could also be used to make navigation directions accessible.

Similarly, D4 asked, "do we want to have a display?" prompting debate on social aspects of accessible navigation:

V4: Or maybe if you have a microphone on it, so that you can ask questions, have like a little switch so you make sure that it's off when it should be off.

S4: Actually, if it's in your wrist, do you really need an earpiece, can't you just like do the Dick Tracy phone thing?

D4: Well, I guess-you know, that's a good question, let's talk about that for a minute here. So, one of the things we had originally talked about was that... you would get information... served to you based on your location, so if you walked by the lounge, it would say, hey you're at the lounge, this is what's going on right now. You can go in or not. So we would be taking away that kind of ambient information, but you know, that's a tradeoff. -Workshop 4, Task 2

D4 identified a tradeoff between providing information through audio cues and the ability to hear ambient noises. Eventually, V4 validated the tradeoff for access:

\section{S4: What if the earpiece was optional?}

D4: Yeah I think-I think that-yes. So, optional earpiece... Because then maybe that would be potentially more helpful to a visually impaired user.

S4: And also more useful to-some people will want an earpiece just because they're like, well this is so much easier, it's like one of those Bluetooth headphones. And other people'd be like, that would look terrible with my earrings, I would rather be able to just hold my wrist up to my ear.

V4: And people think that blind people have perfect hearing, and we don't. You know, some of us have hearing losses and this and that. It depends on the cause of blindness and a lot of times earbuds will block your hearing, that's why some people have gotten really excited about the bone conductor headphones. They're kind of expensive, I've heard they're like $\$ 300 \ldots$ Cause the thing is, you don't want all your hearing blocked, cause you're using your hearing to navigate.

D4: Right, oh! That's a great consideration. So if you have an earpiece all the time, you know there's other ambient sound that would be helpful for you just to navigate around, 
and if you have an earpiece, you're obfuscating, you know, your ability to kind of take in the ambient sound. Oh, that's good. -Workshop 4, Task 2

Above, participants' discussion led to access made on assumptions of the abilities of blind people, i.e., V4 raised and debunked the myth that, "people think blind people have perfect hearing, and we don't." The mix of issues-social, functional, disabled, nondisabled - led them to recognize the need to access ambient sound and navigation information.

These examples show how questions about social and functional situations prompted discussions that yielded creative ideas to address the "duality" of accessible design. Thus, we observed that prioritizing social factors did not seem to take away from moving toward a viable solution. The focus on social aspects also did not inhibit discussions about functionality. Instead, participants shifted focus toward functional solutions that adhered to their social preferences (i.e., wrist watch form factor and Bluetooth technology). Next, we show how the designers' ability to elicit and balance responses from both users contributed to productive and open-minded ideation.

\section{How Designers Balance User Voices}

Working with two users influenced interpersonal dynamics and, consequently, the design process itself. Designers were surprised that working with two users enabled them to work quickly. D4 contrasted working with one user at a time:

I think what would happen is one person or the otherindividually, you would come up with a design. So you might come up with multiple designs, which is cool because then you have multiple candidates. But here, we had-I thinkalmost a best candidate emerge more rapidly which I think was helpful. $-D 4$, Interview

Designers noted the immediacy with which they exchanged ideas made the difference in addressing details. Below, D3 began with a question about options, and the discussion evolved to preferences for similar functionality (Figure 7).

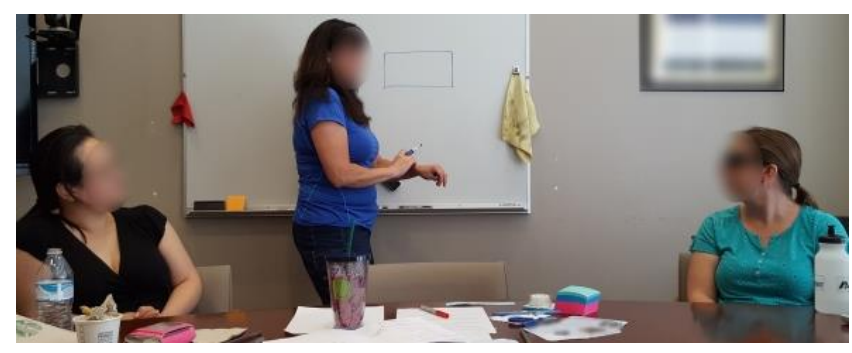

Figure 7. D3 confers with both users during brainstorming.

D3: So,... either you could hit the button, and then it wakes up, or you could voice activate it, so you could do both ways.

V3: I think you should also [activate] by just tapping the screen in case we have people with orthopedic challenges?

S3: What if the whole screen taps? Because the way-like the mouse on the MacBooks, the whole mouse pad is a clicker.
V3: Right. Yeah, that's-I was just thinking-cause one of the things I didn't like about the Apple Watch is that you had to press and hold the little rotating dial to get Siri to listen to you... and it would have been neat if I could have just press and held on the-on the touch screen. -Workshop 3, Task 2

The above example demonstrates how quickly colocation aided ideation, often with a single prompt from the designer. Such prompts also guided users to reflect and progress ideas:

D1: Or people who are in wheelchairs, or if you can't really see the screen, how will you interact with that? So, like what's a good workaround for it?

S1: Well, I'm thinking - because even I think it's hard, tooknowing where to scan. I mean, sometimes you're even at the grocery store and you're like scanning and scanning and scanning-something's not happening, but maybe if there's like a sensor or a buzzer that like-like your watch buzzed when you were nearby one, so that it just like alerts you to the fact that you're close by.

\section{D1: Okay, so something like tactile feedback.}

S1: Although, I feel like that could get annoying if you're walking around. So, obviously, you could turn it off or on, or something. So if you needed to find one, you'd turn it on so that you could just have your wrist out, but...

G: I don't know how feasible this would be, but considering the weight of a kiosk, but have you guys ever seen those desks that you could just like rise and if the kiosk itself were like on a rising or swivel-out thing, I think ...probably figuring out where to grab, like maybe you could have some ridges or something. -Workshop 1, Task 1

D1 clarified S1's thinking, rephrasing what S1 said as "tactile feedback." S1 reflected with, "I feel like that could get annoying..." Returning the idea as tactile feedback gave S1 a chance to debate different aspects of using that mode. The conversation led $\mathrm{V} 1$ to propose the screen as adjustable, not just requiring users to match its placement.

Colocation also provided an opportunity for designers to balance complex multiple perspectives at the intersection of accessible design in real-time. Visually impaired users were likely to comment on navigation issues as a key concern, and various voice and touch interactions were discussed. Sighted users were likely to admit they were not keen on voice commands, accessing information by touch and sight was sufficient. Ideas bounced back and forth quickly between users, providing insights into what worked (or did not work) for visually-impaired users versus what worked (or did not work) for sighted users. Designers managed both viewpoints by switching focus on ideas as they were discussed.

S2: Well, for me specifically - but I don't have an impairment where I can... I can actually look at a map, look at it for a few seconds, put it away. Okay, I think I took a wrong turn, pull it back out-That's not an issue for me as much as it may 
be for others, or, you know, with the voice commands, I don't use that as much. But it's a technology I have.

D2: Um hm. (to V2) And you said you would prefer something that's actually more voice based, that tells you, you need to walk 50 steps down and then 50 feet and then take a left, and then that's like the first room on the right, instead?

V2: Um, yeah, in general I find maps hard to use just because of the size. And, in addition, I have to pull these out so I'm always carrying this extra stuff. I can't just kind of be carefree.

D2: Uh okay, so you say something that's voice driven would actually help you?

V2: Sure. Um, I mean if it was something where if I had enough vision without these-I lug my purse with me everywhere cause it has my stylus, it has my phone, it has my 3 inch thick glasses. Um, if I didn't have to do that and I could-if I was given a phone, on a cruise ship, and I knew that the big round green button in the upper left was voice information, and I could just tap on that and then say, where is the bathroom? Where is the closest bathroom? And the voice guided me, that would be really, really helpful. Workshop 2, Task 2

D2's line of questioning emerged as a response to S2's explanation that using a map was convenient. In his interview, D2 reflected why he sought both views: "It was a question of balancing. I guess what I was really trying to figure out was, would she, S2, use something that V2 would actually use?" D2 prompted ideas from both and sought clarity about how maps are difficult (why voice input is useful for V2). Thus, for their part, designers solicited perspectives to inform a central idea.

Designers admitted that the ability for users to get along was key in eliciting useful information. We observed a genial tone between participants, such as when users volunteered preferences, and conversed without designer interference. D2 expressed a concern that one user might dominate:

The good thing was, both of them were really responsive. The challenge is if one of them is really gregarious and one is super quiet. Then you're just getting feedback from one person. That-thankfully that didn't happen. But I've seen that happen in the past and you have just one very dominant respondent in the group who just takes over the whole challenge. $-D 2$, Interview

D5's take on how user interactions evolved in the workshop aligns with D2's perspective:

They were bouncing ideas off each other, and that was really cool to see. And, they presented what would be good for them and what wouldn't be good for them, but they also recognized how other people not in their situation would utilize the design. $-D 5$, Interview
The ability for users to get along was key for designers to engage ideas. Those recruited for the study may have been characteristically genial and assertive; still, we observed that respectful interactions made for productive discussions. The presence of both users resulted in more than the sum of their perspectives as designers learned from users' interactions.

\section{How Designers Situated Experiences in Workshops}

We interviewed designers to situate their professional roles in their workshop experience. We recruited designers who did not specialize in accessibility, though some encountered accessibility in their work (D2, D3, D4 reported addressing accessibility only for legal reasons). Designers reported little experience working with disabled users and that focusing on accessibility was seen as distracting from their priorities. Despite limited exposure to disability and accessibility, and some initial apprehension about working with multiple users in the given time, interviews revealed that designers felt comfortable with design tasks and showed how their thinking about accessible design evolved.

Designers initially did not feel confident in their ability to manage multiple users at once. For example, D5 reflected:

...the design task was not uncomfortable. Yeah. Um, I think being exposed to both the physically disabled and nonphysically disabled people working together has improved my perception of design with disabilities... it was comfortable, like being in the same room, definitely. But in terms of facilitating. I wasn't sure if I was comfortable or not. But that's probably just on me. -D5, Interview

While design tasks were not daunting, constraints like time and multiple users at first seemed challenging to designers.

I think it certainly was eye opening. Again, I hadn't had this-when I first saw that time sheet, I was like, oh crap, there's just-what the hell are we gonna come up with, it's going to be complete garbage. And I think we came up with something that...had some potential. $-D 4$, Interview

When asked if it was useful to work with two users, designers reflected on how working with visually impaired and sighted users helped ensure perspectives from both were included:

If you want to design something that's inclusive, you have to have both parties involved, right? So that was good. Um, so that's why I'm surprised about-what I'm surprised about myself is like, I should be thinking about the nondisabled as well as the disabled rather than just focus on the disabled. D5, Interview

We view these reflections as validating the design prompt and process, specifically working with both users, because it shows how designers engaged each concept.

\section{DISCUSSION}

Our findings show that infusing user-centered design (UCD) with Design for Social Accessibility (DSA) helped designers engage reflective discussions with visually impaired and sighted users on socially accessible aspects of design. Such 
discussions elicited more than the sum of individual perspectives, helping designers incorporate accessibility.

\section{Social Perspectives Benefit Design Process}

Through the lens of the first DSA tenet-examining how designers worked with visually impaired and sighted userswe observed that colocation was effective in helping designers elicit discussions on sensitive social and functional access issues. These discussions expedited the process, allowing "a best candidate to emerge more rapidly," as D4 mentioned $[23,29,36]$. Through the lenses of the second and third DSA tenets - analyzing how designers included social factors and used the DSA framework and method cards-we found that leveraging these tools for social accessibility enabled designers to reflect on multiple perspectives (disabled, nondisabled, social, functional) while engaging the project domain spaces (personal technology use in shared social spaces, i.e., the cruise ship) [6,22]. As D5 reflected, "If you want to design something that's inclusive, you have to have both parties involved, right? ...I should be thinking about the nondisabled as well as the disabled," i.e., the intersection of ideas from both users was necessary to find solutions that worked for both users. Conversations at the intersection of non/disabled users and social/functional considerations provided "a little space for duality," as S5 called it. We interpret duality as a domain space emerging at the intersection of disabled and nondisabled users and social and functional needs. Thus, these strategies and tools eased accessible design by revealing new design opportunities arising from intersecting perspectives. We compare these findings with related work emphasizing empathy [24]: we agree that empathy is key to inclusive design, and effort should also be made to highlight intersecting perspectives (disabled and nondisabled) and design dimensions (social and functional) toward broadening the design domain space.

\section{Toward Socially Accessible Design}

Designers in our study recognized disability as important in design, yet their everyday practice excluded disabled users. Thus, the skill and knowledge that "constitute the rigor and discipline" for these designers were quite without an accessibility or disability component [32]. Still, as observed in how D1 drew on her experiences using the framework, DSA helped the designers "prepare-for-action," i.e., was not prescriptive, but leveraged designer autonomy and expertise within their current design processes [32]. In contrast to challenges faced by students in a design course [29], the professional designers in this study reported feeling comfortable with the design prompt and incorporating DSA, despite having little prior experience working with disabled users. Designers created paper mockups that were evaluated by users as meeting needs, while tackling complex issues (social/functional and non/disabled perspectives). Thus, we argue that infusing UCD with DSA aligned with the designers' expertise, bridging the gap from existing practice to new ways of thinking with tools for accessible design [32]. We outline implications for design practice that emerged:
- The barrier to working with visually impaired users is not so high. Our inquiry showed designers developed accessible solutions for both users even with limited prior experience. We infer that increasing knowledge, awareness and experience-even in small ways, i.e., including visually impaired and sighted users - can improve accessible design.

- Designers' professional expertise enabled them to adapt to work with visually impaired and sighted users quickly: They invoked their preferred techniques while guiding users through complex design considerations.

- Designers do not have to be "accessibility specialists" to include disability in design. Designers ran into some technical unknowns (e.g., some did not know the iPhone is accessible via VoiceOver), but this limitation did not prevent them from creating an accessible solution. Initial lack of technical accessibility knowledge is thus not necessarily a barrier to accessible design, provided an "expert user" with a disability is present.

Given these implications, our study shows that DSA can be used to help designers to create accessible designs.

\section{Study Limitations}

We refrain from making claims that DSA is better than other approaches for accessible design, as our study design was not comparative. Our investigation is limited as a contrived workshop, not a real-world setting. However, our goal was to investigate how including accessibility in the design process might manifest for designers. Our choice to employ a small number of in-depth workshops allowed for a rich dataset, in lieu of a large survey. Future work could involve a comparison of survey results with our findings here.

\section{CONCLUSION}

Changing the culture and practice of design to include disabled users is one way to improve design $[6,7,13,37]$. We examined how infusing user-centered design techniques with Design for Social Accessibility helped designers incorporate accessibility. We showed that including visually-impaired and sighted users, and considering social and functional factors, helped designers envision a new domain space and creative solutions usable and appealing to disabled and nondisabled users. Accessible design is not an impossible challenge; instead, is within reach for professional designers, if given appropriate tools and resources. We offer Design for Social Accessibility as one such tool that designers can use to include disabled and nondisabled users and complex social and functional consideration toward accessible solutions.

\section{ACKNOWLEDGMENTS}

This work was supported in part by the National Science Foundation under IIS-1217627, SES-1230435, IIS-0952786 and the University of Washington Harlan Hahn Award. We thank David Hendry for his early feedback on this work. 


\section{REFERENCES}

1. Jane Bringolf. 2008. Universal design: is it accessible? Multi: The Journal of Plurality and Diversity in Design 1, 2.

2. Julian Brinkley, Brianna Posadas, Julia Woodward, and Juan E. Gilbert. 2017. Opinions and Preferences of Blind and Low Vision Consumers Regarding SelfDriving Vehicles: Results of Focus Group Discussions. In Proc. ASSETS '17, 290-299.

3. Tim Brown. 2008. Design Thinking. Harvard business review 86, 6: 84-92.

4. Sheryl Burgstahler. 2015. Universal design in higher education: from principles to practice. Cambridge, Massachusetts : Harvard Education Press, Cambridge, Massachusetts.

5. Betty Rose Connell, Mike Jones, Ron Mace, Jim Mueller, Abir Mullick, Elaine Ostroff, Jon Sanford, Ed Steinfeld, Molly Story, and Gregg Vanderheiden. 1997. The Principles of Universal Design. Retrieved from https://www.ncsu.edu/ncsu/design/cud/about_ud/udpri nciplestext.htm

6. Nigel Cross. 1982. Designerly ways of knowing. Special Issue Design Education 3, 4: 221-227. https://doi.org/10.1016/0142-694X(82)90040-0

7. Nigel Cross. 2011. Design thinking : understanding how designers think and work. Berg, Oxford; New York.

8. Lennard Davis. 2010. Constructing Normalcy. In The Disability Studies Reader (Third Edition). Taylor \& Francis, 3-19.

9. Jason Dearen. 2018. Driverless cars give hope to blind - are automakers onboard? Sacramento Bee. Retrieved April 17, 2018 from http://www.sacbee.com/news/article208779379.html

10. Elizabeth DePoy and Stephen Gilson. 2014. Branding and designing disability: reconceptualising disability studies. Abingdon, Oxon: Routledge.

11. Barney G. Glaser and Anselm L. Strauss. 1967. The Discovery of Grounded Theory. Aldine Publishing Co, Chicago, IL.

12. Erving Goffman. 1963. Stigma. Englewood Cliffs, N.J., Prentice-Hall, Englewood Cliffs, N.J.

13. Elizabeth Goodman, Erik Stolterman, and Ron Wakkary. 2011. Understanding interaction design practices. In Proc CHI '11, 1061-1070.

14. John D. Gould and Clayton Lewis. 1985. Designing for usability: Key principles and what designers think. CACM 28, 3: 300-311.

15. Joan M. Greenbaum and Morten Kyng. 1991. Design at work: cooperative design of computer systems. Erlbaum Assoc., Hillsdale, N.J.

16. Maya Haynes. 2015. Use Your Head! Microsoft's HoloLens. Aidis Trust Blog. Retrieved from http://blog.aidis.org/use-your-head-microsofts-hololens

17. Cliff Kuang. 2016. Microsoft's Radical Bet on a New Type of Design Thinking. The Big Idea. Retrieved
September 11, 2016 from

https://www.fastcodesign.com/3054927/the-bigidea/microsofts-inspiring-bet-on-a-radical-new-typeof-design-thinking

18. L. Tonin, T. Carlson, R. Leeb, and J. del R. Millán. 2011. Brain-controlled telepresence robot by motordisabled people. In 2011 Annual International Conference of the IEEE Engineering in Medicine and Biology Society, 4227-4230. https://doi.org/10.1109/IEMBS.2011.6091049

19. Richard E. Ladner. 2015. Design for user empowerment. interactions 22, 2: 24-29.

20. Selena Larson. 2016. How Pokemon Go is creating a barrier for gamers with disabilities. The Daily Dot Debug. Retrieved September 11, 2016 from http://www.dailydot.com/debug/pokemon-godisabilities-problematic/

21. Matthew B. Miles and A. M. Huberman. 1994. Qualitative data analysis: an expanded sourcebook. Sage Publications, Thousand Oaks.

22. Harold G Nelson and Erik Stolterman. 2012. The design way: intentional change in an unpredictable world. MIT Press, Cambridge, Massachusetts.

23. Alan Newell, P Gregor, M Morgan, Graham Pullin, and C Macaulay. 2011. User-Sensitive Inclusive Design. Universal Access in the Information Society 10, 3: 235-243.

24. Alan Newell, P Gregor, M Morgan, Graham Pullin, and C Macaulay. 2011. User-Sensitive Inclusive Design. Universal Access in the Information Society 10, 3: 235-243.

25. John Potts and John Scannell. 2013. The unacceptable. Palgrave Macmillan, Houndmills, Basingstoke, Hampshire.

26. Roland Reznik. Disability Advocates See Opportunity in Self Driving Cars. Smart Chair. Retrieved

September 11, 2016 from

http://kdsmartchair.com/blogs/news/110637830disability-advocates-see-opportunity-in-self-drivingcars

27. Helen Sharp, Yvonne Rogers, and Jenny Preece. 2007. Interaction design: beyond human-computer interaction. Wiley, NJ.

28. Kristen Shinohara, Cynthia L. Bennett, Wanda Pratt, and Jacob O. Wobbrock. 2018. Tenets for Social Accessibility: Towards Humanizing Disabled People in Design. ACM Transactions on Accessible Computing (TACCESS) 11, 1: 1-31.

29. Kristen Shinohara, Cynthia L. Bennett, and Jacob O. Wobbrock. 2016. How Designing for People With and Without Disabilities Shapes Student Design Thinking. In Proc. ASSETS '16., 229-237.

30. Kristen Shinohara and Jacob O. Wobbrock. 2011. In the shadow of misperception: Assistive technology use and social interactions. In Proc. CHI '11, 705-714.

31. Kristen Shinohara and Jacob O. Wobbrock. 2016. SelfConscious or Self-Confident? A Diary Study 
Conceptualizing the Social Accessibility of Assistive Technology. ACM Transactions on Accessible Computing (TACCESS) 8, 2: 1-31.

32. Erik Stolterman. 2008. The Nature of Design Practice and Implications for Interaction Design Research. International Journal of Design 2, 1: 55-65.

33. Katherine M. Tsui, Munjal Desai, Holly A. Yanco, and Chris Uhlik. 2011. Exploring use cases for telepresence robots. In Proceedings of the 6th international conference on Human-robot interaction, 11-18.

34. Chris Urmson. 2015. Green lights for our self-driving vehicle prototypes. Google Blog. Retrieved September 11, 2016 from https://googleblog.blogspot.com/2015/05/self-drivingvehicle-prototypes-on-road.html
35. Jacob O. Wobbrock, Krzysztof Z. Gajos, Shaun K. Kane, and Gregg C. Vanderheiden. 2018. Abilitybased design. Communnications of the ACM 61, 6: 6271.

36. Jacob O. Wobbrock, Shaun K. Kane, Krzysztof Z. Gajos, Susumu Harada, and Jon Froehlich. 2011. Ability-based design: Concept, principles, and examples. ACM Transactions on Accessible Computing (TACCESS) 3, 3: 1-27.

37. Xiao Zhang and Ron Wakkary. 2014. Understanding the role of designers' personal experiences in interaction design practice. In Proc. DIS '14, 895-904. 